\title{
Modelling and Decision-Making Methods in Internet Marketing: Advertising Budget Efficiency and Advertising Quality
}

\author{
Sukharev O. S., Kurmanov N.V." \\ The Institute of Economy of Russian Academy of Sciences \\ *Corresponding Author: nik@kurmanov.com
}

Copyright $@ 2013$ Horizon Research Publishing All rights reserved.

\begin{abstract}
This research is devoted to the methods and models of decision-making in marketing, substantiation of mathematical similarity theory application in factor analysis of market situation (demand for production) while selling via Internet. Russian timber industry enterprises were the object of the research. Demand function was obtained empirically at these enterprises. Factor analysis methods within the Internet marketing system at the enterprises are suggested. The review of decision-making methods and models in marketing, their comparative analysis is made. Modification of Danaher-Rust model applied to quality estimation of advertising on the company's site is carried out.
\end{abstract}

Keywords Models of Marketing Decision Making, Factor Model of Production Demand and Sales Function in the Internet, Similarity Theory, Models of Advertising Budget Estimation, Marketing Activity Efficiency

\section{Basic Marketing Tools and Estimation Methods of Effective Advertising Budget}

The basic marketing tools are known to be $[1,2,5]$ :

-Market research (estimation of market capacity and quantitative characteristics of demand elasticity, market segmentation, estimation of the curve kind and phases of product life cycle);

- Commodity strategy (production quality, production volumes, production assortment);

- Price strategy (price for a product, transactions conditions);

- Marketing strategy (marketing channels, warehouses, transport, wholesale and retail trade);

- Promotion - advertising, public relations, publicity, demand stimulation, personal sales and sales promotion.

Analysis of the methods of demand and advertising budget estimation applied now has shown that they are frequently based on common sense, experience and intuition, but sometimes such approach leads to the situation when advertising is paid either less or more than it is necessary. Both variants are inefficient.

Let's consider the methods of advertising budget estimation supplementing each other which are applied in media planning.

Method 1 (in percent to sales amount). Percentage indicator of advertising costs to total sales costs is used more often. Indicator "advertising/sale" in itself is not a defining factor. It is a numerical expression of two variables correlation. Indicator "advertising/sale" can be deduced on the basis of past experience. Invariability of one and the same indicator presupposes the necessity to spend more or less on advertising for the sake of planned sales level. Indicator "advertising/sale" is frequently formed subject to competitors' similar correlations. The advantages of this method are:

- The firm allocates the available quantity of means; relationship between advertising costs and profit received from sale is taken into consideration;

- The method favors stability in industry and normal competition level as it is supposed, that all the firms spend the same percent of the turnover for advertising;

- Collective experience is taken into account, though it is necessary to bear in mind that advertising expenses level of competitors can be non-optimal (competitors can be mistaken in their calculations and draw a false conclusion).

Disadvantage of the planning method of allocation for advertising in percent to sales volume is the fact that sale is the reason, and advertising is a consequence.

Method 2 (subject to the purposes and goals). Taking into account the purposes and problems the primary attention is paid to the purposes which are necessary for the firm to achieve and the role of advertising in it. Applying this method advertising is not considered as a consequence, but as the reason of sales.

Method 3 (according to the leftover means). The way of leftover means is that the firm allocates as much means for advertising, as it is left after its distribution for all other 
needs.

Method 4 (subject to the practice of competing firms). This way stipulates forming of advertising budget so that advertising is competitive. For this purpose it is necessary, that the amount of money allocated for advertising is comparable and competitive. Usually they proceed from the average amount in this sphere of business.

Method 5 (the method of shareholding in the market). In many cases the firm's management is aware of competitors' advertising expenses and it tries to have approximately the same expenses. Under such conditions planning the expenses the firm should take into consideration probable retaliatory actions (reaction) of the competitors.

This method is based on the following assumption: other things being equal, distribution of the general market capacity between separate firms eventually becomes proportional to the shares of these firms in total advertising expenses.

Method 6 (based on the use of mathematical models of decision-making). The methods based on the use of mathematical models of decision-making are widely used now at working out of the demand volume. Use of these methods is caused by the fact that a person cannot estimate and take into account a considerable quantity of factors. Therefore, use of mathematical methods of decision-making, special software and computer becomes actual. We will consider several different approaches to sizing of advertising budget based on mathematical models of decision-making in series.

\section{Mathematical Models of Decision-Making in Marketing}

Vidal-Wolf Model. One of the first models of this type is developed by M.Vidal and H.Wolf $[8,21,22]$. In this model change of the goods sales volume at time $t$ is the function of four factors: advertising expenses; constants expressing sales reaction on advertising; saturation level of the market with advertised goods and constants expressing the reduction of sales volume.

The basic equation of the model (advertising budget according to Vidal-Wolf formula) is as follows [8,21, 22]:

$$
\mathrm{Rb}=(\Delta \mathrm{S}+\mathrm{k} 2 \cdot \mathrm{S} 0) / \mathrm{k} 1 \cdot \mathrm{Smax} /(\mathrm{S} m a x-\mathrm{S} 0)
$$

where $R_{b}$ - advertising budget volume;

$\Delta \mathrm{S}$ - change of sales volume level in comparison with the current one;

$k_{1}$ - reaction constant of advertising turnover;

$S_{\max }$ - saturation level of the market with the good (job, service);

$S_{0}$ - current sales volume;

$k_{2}$ - constant of the reduction of sales volume in the absence of advertising expenses.

The basic advantage of Vidal-Wolf model is that it is possible to describe the relationship of three factors: amount of allocation on advertising, sales volume and its change under the influence of advertising. The disadvantages of the given approach are:

- The model does not allow considering other marketing variables such as price and sales system in the explicit form;

- The actions of competitors are not considered in the model;

- It may be difficult to estimate saturation level of some market.

Model ADBUDG. Model ADBUDG [9,10] developed by Little is oriented on the stable market with non-extendible global demand for which advertising is a determinant of sales increase or market share growth. According to this model the expected market share is three factors function:

- The minimum market share $P_{\min }$, that is, the market share in the end of the examined period without advertising;

- Parts of the minimum change of the market share under the influence of advertising. This maximum change is equal to the difference between the expected market share at the highest level of advertising and the minimum market share provided by advertising absence;

- Advertising intensity coefficient set by two parametres, one of them is sensitivity coefficient of the reaction function $g$ (it defines the character of the reaction function) and the second is attenuation factor $d$ (it characterizes attenuation at maximum and minimum advertising intensity. It tends to 1 or to 0 accordingly) $[9,10]$.

In this method the following formula is used as the basic one

$$
P=P_{\text {min }}+\left(P_{\text {max }}-P_{\text {min }}\right) \cdot \frac{E_{A}^{g}}{d+E_{A}^{g}}
$$

where $P$ - market share desirable for the firm; $P_{\min }$ - market share which the firm will have at zero advertising $\left(\mathrm{E}_{\mathrm{A}}=0\right)$;

$P_{\max }$ - market share which the firm will have at the highest level of advertising ( $\mathrm{E}_{\mathrm{A}}$ tends to infinity);

$g$ - sensitivity coefficient of the reaction function;

$d$ - attenuation factor;

$E_{A}$ - advertising intensity factor.

Hence it is easy to find advertising budget value

$$
E_{A}=\left[\frac{d \cdot\left(P-P_{\min }\right)}{P_{\max }-P}\right]^{1 / g}
$$

It is not difficult to notice, that size of the firm's market share is none other than the relation of firm's turnover to the saturation level of the goods market (it is similar to value $S_{\max }$ in Vidal-Wolf model)

$$
P=\frac{S}{S_{\max }}
$$

Then, using formula (1) it is possible to write down

$$
S=S_{\text {min }}+\left(S_{\text {max }}-S_{\text {min }}\right) \cdot \frac{E_{A}^{g}}{d+E_{A}^{g}}
$$


where $S$ - desirable firm's turnover;

$S_{\text {min }}$ - firm's turnover at zero advertising;

$S_{\text {max }}$ - firm's turnover at the highest advertising level.

Common disadvantages characteristic for calculation methods of advertising budget depending on the turnover are:

- dependence of turnover on advertising budget has either linear character, or nonlinear character (method ADBUDG);

- there are from 1 to 4 factors (both linearly dependent and linearly independent between themselves) in these dependences. From the mathematical point of view to find these factors it is necessary to know, first, the quantity of dependence points $S=f\left(E_{A}\right)$ equal to the quantity of linearly independent factors, and, secondly, to solve the system of equations concerning these factors.

Yule Model. Advertising budget according to Yule formula $[2,8]$ is

$$
\mathrm{Rb}=\mathrm{p} \cdot \mathrm{n} 0 \cdot(1 /(\mathrm{k} 0 \cdot \mathrm{k}) \cdot(\mathrm{N} / \mathrm{Nmax}),
$$

where $R_{b}$ - advertising budget;

$\mathrm{p}$ - cost of one, so-called, rating unit;

$n_{0}$ - quantity of the rating units necessary for relative $100 \%$ of target audience coverage;

$N_{\max }$-quantity of firm-advertiser's potential clients;

$N$ - quantity of the firm's constant clients;

$k$ - relation of the quantity of the firm's clients who has become regular customer to the quantity of clients who will buy the goods of this firm;

$k_{0}$ - relation of the quantity of clients, who will buy the goods of this firm to the quantity of those, who has seen advertising of this firm.

Yule model is a consequence of determination method of advertising budget volume taking into account the purposes and goals the basis of which is the turnover of the goods, and in Yule model this value is substituted with clients quantity. Such change demonstrates more justified results.

Determination method of advertising budget volume in percentage to the sales volume. By this method advertising budget is estimated regarding the present turnover $[8,10,11]$

$$
\mathrm{EA}=\mathrm{k} \cdot \mathrm{S} 0
$$

where $E_{A}$ - advertising budget (advertising expenses); $k$ - indicator of advertising allocations regarding the sales volume existing in the market (or in the firm);

$S_{0}$ - firm's turnover at the moment of advertising budget estimation.

Let's assume the firm's sales volume to be 10 million rubles. The percentage indicator of allocation on advertising from a turnover existing in the market is $5 \%$. Then advertising budget will be 500 thousand rubles.

The only advantage of this method is its accessibility.

Determination method of advertising budget volume taking into account the purposes and goals. Determination method of advertising budget volume taking into account the purposes and goals is presented in literature in detail $[14,15,18]$.
Advertising budget $E_{A}$ can be presented in a linear form:

$$
E_{A}=p \cdot n_{0} \cdot \frac{S}{S_{\max }}
$$

where $p$ - cost of one, so-called, rating unit;

$n_{0}$ - quantity of the rating units necessary for relative $100 \%$ of target audience coverage;

$S$ - desirable sales volume level;

$S_{\max }$ - maximum sales volume level (relative $100 \%$ target audience coverage).

Using the enumerated methods which are oriented on advertising budget, it is possible to define the demand volume. For this purpose it is necessary to introduce additional mathematical transformations. But these methods do not take into consideration a number of factors (with regard to Internet marketing) which can make weighty enough changes in the existing market system. Therefore, there is a necessity to work out a new model which would consider sufficient number of factors, thereby most accurately reflecting change dynamics in the market.

\section{Mathematical Modeling According to the Similarity Theory}

Mathematical volume model of production demand. For mathematical modeling on the basis of the similarity theory the following scheme is used [23,24]. On the first stage we make a choice of the factors influencing the demand volume according to the first similarity theorem.

To choose factors it is necessary to know what parameters appear in the experiment; how to process the results; what phenomena are similar to the process studied. It is necessary to measure parameters which are contained in the similarity criteria of the studied phenomenon in the experiments. Factors necessary for modeling are received as a result of rank correlation method, hence, on the basis of a priori diagrams.

Let's introduce the symbols: $\mathrm{B}_{\Phi}$ - budget for functional perfection; $\mathrm{B}_{\Pi}$ - budget for sales promotion; $\mathrm{N}_{\mathrm{P}}$ - number of site hits (people); $\mathrm{N}_{\mathrm{S}}$ - production demand volume (people); $\mathrm{G}$ - search system algorithm; R - user's estimation of the site; $\mathrm{S}$ - advertising position; $\mathrm{H}$ - level of confidence to the enterprise; $\mathrm{Re}_{\mathrm{K}}$ - content relevance; $\mathrm{Re}_{\mathrm{i}}$ - information relevance.

Such factors as the user's estimation of the site (R), advertising position (S) and level of confidence to the enterprise $(\mathrm{H})$ have units of measurement conventional enough and, consequently, they can be united by the following functional dependence called confidence module $\Psi$ :

$$
\Psi=\text { R S H. }
$$

These factors are responsible, first of all, for confidence to the data and the enterprise, i.e. for content relevance of the site. Thereby, the product of these factors will be like 
"efficiency" (coefficient of efficiency) of complex system, and, as is known, efficiency of complex system is equal to the product of efficiency of each mechanism separately (Table 1.).

Table 1. Factors and Their Variation Levels

\begin{tabular}{|c|c|c|}
\hline Factor & Size Symbol & $\begin{array}{c}\text { Dimension and Variation } \\
\text { Interval }\end{array}$ \\
\hline $\begin{array}{c}\text { The budget for } \\
\text { functional perfection }\end{array}$ & $\mathrm{B}_{\Phi}$ & $\begin{array}{c}\text { ruble } \\
{[100,100000]}\end{array}$ \\
\hline $\begin{array}{c}\text { The budget for sales } \\
\text { promotion }\end{array}$ & $\mathrm{B}_{\Pi}$ & $\begin{array}{c}\text { ruble } \\
{[100,100000]}\end{array}$ \\
\hline $\begin{array}{c}\text { Number of site hits } \\
\text { people } \\
{[40,50000]}\end{array}$ \\
\hline $\begin{array}{c}\text { Production demand } \\
\text { volume }\end{array}$ & $\mathrm{N}_{\mathrm{P}}$ & $\begin{array}{c}\text { people } \\
\text { Statistical information }\end{array}$ \\
\hline Search system algorithm & $\mathrm{G}$ & $\begin{array}{c}\% \\
{[0,100]}\end{array}$ \\
\hline Content relevance & $\mathrm{Re}_{\mathrm{K}}$ & $\begin{array}{c}\% \\
{[0,100]}\end{array}$ \\
\hline Information Relevance & $\mathrm{Re}_{\mathrm{i}}$ & $\begin{array}{c}\% \\
{[0,100]}\end{array}$ \\
\hline Confidence module & $\Psi$ & $0,100]$ \\
\hline
\end{tabular}

On the second stage of the scheme of demand volume modeling we define the number of similarity criteria (dimensionless groups). We will define the number of groups according to Buckingham theorem $[23,24]$.

The number of similarity criteria of (simplexes) is equal to

$$
\mathrm{n}_{\text {пр.п }}=\mathrm{n}_{\phi}-\mathrm{n}_{\mathrm{oc}}
$$

where $n_{n p . n}$ - number of similarity criteria;

$n_{\phi}$ - number of factors;

$n_{o c}$ - number of basic units (econometrics in this case).

Then $n_{n p . n}=8-1=7$.

On the third stage we define the kind of similarity criteria using elimination approach:

- the criterion taking into account production demand volume and the number of site hits

$$
\pi_{1}=\frac{N_{S}}{N_{P}}
$$

where $\mathrm{N}_{\mathrm{S}}$ - production demand volume, people (it is chosen from the statistical data referring to the enterprises of timber processing complex over a six months' period);

$\mathrm{N}_{\mathrm{P}}$ - number of site hits, people (it is chosen proceeding from statistical treatment).

Considering the interval (Table 1) for the number of site hits $N_{P}$ - [40,50000], we will make partition of the interval into groups of separate segments. We will define the number of such groups $\mathrm{n}$ according to Sturgess formula

$$
\mathrm{n}=1+3,322 \cdot 1_{\mathrm{g}} \mathrm{N}_{\max }
$$

where $l g$ - decimal logarithm;

$N_{\max }$ - maximum number of site hits in the interval [40,50000]; $N_{\max }=50000$ hits (Table 1);

$n$ - number of groups (separate segments).

Using the maximum number of site hits, we will get the number of separate segments into which the interval
$[40,50000]$ is divided:

$$
\mathrm{n}=1+3,322 \cdot \lg 50000=17
$$

Thus, we will define the length of separate segments $h$ into which the interval of the number of site hits is divided as follows

$$
h=\frac{N_{\max }-N_{\min }}{\mathrm{n}}
$$

where $N_{\max }$ - maximum number of site hits (Table 1) in the interval [40,50000];

$N_{\text {min }}$ - minimum number of site hits (Table 1) in the interval [40,50000].

Let's make partition of the interval $[40,50000]$ into separate segments $(n=17)$ with a step

$$
h=\frac{50000-40}{17}=2938:
$$

1 - [40;2978]; 2 - [2978, 5916];

3 - [5916, 8854];4 - [8854; 11792];

5 - [11792; 14730]; 6 - [14730; 17668];

7 - [17668; 20606]; 8 - [20606; 23544];

9 - [23544;26482];10 - [26482;29420];

11 - $[29420 ; 32358] ; 12$ - [32358; 35296];

13 - [35296; 38234]; 14 - [38234; 41172];

15 - [41172; 44110];16 - [44110; 47048];

17 - $[47048 ; 49986]$.

From this variety of values we will choose six values of the number of site hits $N_{P}$ as the number of similarity criteria is seven, and the number of values of each similarity criterion is defined as $n_{n p . n^{-}}-1=7-1=6$ and, in its turn, is equal to the number of exponents in the record of final criterion equation.

We will estimate the number of site hits according to the average values of chosen intervals. The intervals are chosen using random sampling technique. On the basis of statistical data the number of companies' sites hits is on the average not less than 4000 and not more than 40000 (it is characteristic for regions). Therefore, we will choose the following intervals:

$$
\begin{aligned}
& 2 \text { - }[2978,5916] ; 4 \text { - [8854; 11792]; } \\
& 6 \text { - [14730; 17668]; } 8 \text { - [20606; 23544]; } \\
& 10 \text { - [26482; 29420]; } 12 \text { - [32358; 35296]. }
\end{aligned}
$$

The average values of these six intervals will be the number of site hits $N_{P}$ (Table 2).

Table 2. nput Data for Calculation of Criterion $\pi_{1}$

\begin{tabular}{|c|c|c|}
\hline $\begin{array}{c}\text { Production Demand } \\
\text { Volume, people, } N_{S}\end{array}$ & $\begin{array}{c}\text { Number of Site Hits, } \\
\text { people, } N_{P}\end{array}$ & $\begin{array}{c}\text { Criterion } \\
\pi_{I}\end{array}$ \\
\hline 1979 & 4447 & 0,44 \\
\hline 2449 & 10323 & 0,24 \\
\hline 2628 & 16199 & 0,16 \\
\hline 2164 & 22075 & 0,1 \\
\hline 2685 & 27951 & 0,1 \\
\hline 3037 & 33827 & 0,09 \\
\hline
\end{tabular}


We will choose production demand volume $N_{S}$ from the statistical data presented in the Internet over 2011. Input data and calculation results $\pi_{1}$ are tabulated.

The criterion considering the budget on functional perfection and the budget on sales promotion

$$
\pi_{2}=\frac{B_{I I}}{B_{\phi}}
$$

where $\mathrm{B}_{\Phi}$ - budget on functional perfection, rbl.;

$\mathrm{B}_{\Pi}$ - budget on sales promotion, rbl.

We will make partition of intervals (Table 1) corresponding to the budget on functional perfection $\mathrm{B}_{\Phi}$ and the budget on sales promotion $B_{\Pi}$ into separate segments similarly to partition of intervals for the number of site hits $N_{P}$. As intervals for $\mathrm{B}_{\Phi}$ and $\mathrm{B}_{\Pi}$ are identical $[100,100000]$, then the number of separate segments is also identical. We will make partition of interval $[100,100000]$ into separate segments according to the same above-stated technique ( $n$ $=1+3,322 \cdot \lg 100000=1+3,322 \cdot 5=18)$ with the step

$$
h=\frac{x_{\max }-x_{\min }}{\mathrm{n}}=\frac{99900}{18}=5550:
$$

1 - [100;5650]; 2 - [5650;11200]; 3 - [11200, 16750]; 4 [16750; 22300];

5 - $[22300 ; 27850] ; 6$ - [27850; 33400]; 7 - [33400; 38950];

8 - [38950; 44500]; 9 - [44500; 50050]; 10 - [50050; 55600];

$11-[55600 ; 61150] ; 12-[61150 ; 66700] ; 13-[66700 ;$ 72250];

$14-[72250 ; 77800] ; 15-[77800 ; 83350] ; 16-[83350 ;$ $88900] ;$

17 - [88900; 94450]; 18 - [94450; 100000].

To cover all the interval of values $[100,100000]$ we will apply ranged rank: we will write out the beginnings and the endings of separate segments in increasing order, considering the choice arbitrariness of the reference point (in this case it is 5650) as both budget for functional development, and budget for sales promotion are not $100 \mathrm{rbl}$.

For convenience we will break it into three of values:

1 - $(5650,11200,16750) ; 2$ - $(22300,27850 ; 33400) ; 3$ $(38950,44500,50050)$;

4 - (55650, 61150, 66700); 5 - (72250, 77800, 83350); 6 $(88900,94450,100000)$.

For each three we will find the average and maximum values subject to $n_{n p . n}-1=7-1=6$. From each separated three we will choose the average values - $\mathrm{x}_{\mathrm{cp}}$ for functional perfection budget, and we will choose the maximum values $\mathrm{x}_{\max }$ for sales promotion budget:

1 - $\left(\mathrm{x}_{\mathrm{cp}}=11200 ; \mathrm{x}_{\max }=16500\right) ; 2$ - ( $\left.\mathrm{x}_{\mathrm{cp}}=27850 ; \mathrm{x}_{\max }=33400\right)$;

3 - $\left(\mathrm{x}_{\mathrm{cp}}=44500 ; \mathrm{x}_{\max }=50050\right) ; 4$ - $\left(\mathrm{x}_{\mathrm{cp}}=61150 ; \mathrm{x}_{\max }=66700\right)$;

5 - $\left(\mathrm{x}_{\mathrm{cp}}=77800 ; \mathrm{x}_{\max }=83350\right) ; 6-\left(\mathrm{x}_{\mathrm{cp}}=94450 ; \mathrm{x}_{\max }=100000\right)$.

Then, the formula for similarity criterion $\pi_{2}$ will look like:

$$
\pi_{2}=\frac{B_{\phi}}{B_{\Pi}}=\frac{x_{c p}}{x_{\max }}
$$

Input data and calculation results $\pi_{2}$ are tabulated.

Table 3. Input Data for Calculation of Criterion $\pi_{2}$

\begin{tabular}{|c|c|c|}
\hline $\begin{array}{c}\text { Budget on Functional } \\
\text { Perfection, rbl., } B_{\Phi}\end{array}$ & $\begin{array}{c}\text { Budget on Sales } \\
\text { Promotion, rbl., } B_{\Pi}\end{array}$ & Criterion $\pi_{2}$ \\
\hline 11200 & 16750 & 0,67 \\
\hline 27850 & 33400 & 0.83 \\
\hline 44500 & 50050 & 0.89 \\
\hline 61150 & 66700 & 0,92 \\
\hline 77800 & 83350 & 0,93 \\
\hline 94450 & 100000 & 0,94 \\
\hline
\end{tabular}

- the criterion considering confidence module (users' site estimation, level of confidence and advertising position)

$$
\pi_{3}=\psi
$$

where $\Psi$ - confidence module, it is calculated according to the formula given above.

We will define the users' site estimation $R$ as an average estimation of values sampling in the interval $[1 ; 5]$

$$
R=\frac{1+2+3+4+5}{5}=3
$$

We will define advertising position $S$ the value of which is in the interval $[0,01 ; 1]$ in the same way as the users' site estimation

$$
S=\frac{0,01+0,02+0,03+\ldots . .+0,99+1}{100}=0,5 .
$$

The level of confidence to advertisement $H$ has the same interval, as the users' site estimation, then

$$
H=\frac{0,01+0,02+0,03+\ldots . .+0,99+1}{100}=0,5
$$

Hence, the confidence module will be:

$\Psi=0,5 \cdot 0,5 \cdot 3=0,75$.

- the criterion considering the search system algorithm (Table 4):

$$
\pi_{4}=G
$$

where $\mathrm{G}$ - search system algorithm, \%.

Table 4. Input Data for Calculation of Criterion $\pi_{3}$

\begin{tabular}{|c|c|c|c|c|}
\hline Search system & Yandex & Google & Mail & $\begin{array}{c}\text { The } \\
\text { others }\end{array}$ \\
\hline Statistical data & 51,28 & 31,74 & 9,54 & 7,45 \\
\hline $\begin{array}{c}\text { Marketing } \\
\text { researches }\end{array}$ & 56,96 & 32,413 & 7,28 & 3,34 \\
\hline Average value & 54,12 & 32,0756 & 8,41 & 5,395 \\
\hline
\end{tabular}


We will estimate the results according to the average selective values presented in Table 4.

$$
G=\frac{54,12+32,077+8,41+5,395}{4 \cdot 100}=0,25 .
$$

- the criterion considering content relevance

$$
\pi_{5}=\mathrm{Re}_{K}
$$

where $\mathrm{Re}_{\mathrm{K}}$ - content relevance, $\%$.

Subject to the interval of content relevance $[0,100 \%]$ or in shares $[0,01 ; 1]$, we will make partition of the interval into separate segments, having defined the number of groups according to Sturgess formula:

$$
\mathrm{n}=1+3,322 \cdot \lg 100=8 .
$$

We need $n_{n p . n^{-}}=7-1=6$ values to draw up similarity criteria and their values. We will consider eight separate segments into which interval [0,01 is divided; 1$]$ :

1 - $[0,01 ; 0,13] ; 2$ - $[0,13 ; 0,25] ; 3$ - $[0,25 ; 0,37] ; 4[0,37$; $0,49]$

5 - $[0,49 ; 0,61] ; 6$ - $[0,61 ; 0,73] ; 7$ - $[0,73 ; 0,85] ; 8$ - $[0,85 ;$ $0,97]$.

The length of segments is calculated subject to the condition

$$
h=\frac{x_{\max }-x_{\min }}{\mathrm{n}}=\frac{1-0,01}{8}=0,12 .
$$

Let's choose six intervals by random sampling and subject to the fact that content relevance in most cases is not less than 0,15 :

$2-[0,13 ; 0,25], 4-[0,37 ; 0,49] ; 5-[0,49 ; 0,61]$

$6-[0,61 ; 0,73] ; 7-[0,73 ; 0,85] ; 8-[0,85 ; 0,97]$

We will make estimation on an average for the limit $[0,01$; $0,5]$ which intervals 2 and 4 are a part of.

These values are equal to accordingly:

$$
\begin{aligned}
& \operatorname{Re}_{K 1}=\frac{0,13+0,25}{2}=0,19 ; \\
& \operatorname{Re}_{K 2}=\frac{0,37+0,49}{2}=0,43
\end{aligned}
$$

We will estimate the other values from intervals 5; 6, 7 and 8 on the maximum values and we will get the corresponding data: 0,$61 ; 0,73 ; 0,85 ; 0,97$.

We will tabulate the obtained data.

Table 5. Criterion Considering Content Relevance $\pi_{5}$

\begin{tabular}{|l|l|l|l|l|l|l|}
\hline$\pi_{5}$ & 0,19 & 0,43 & 0,61 & 0,73 & 0,85 & 0,97 \\
\hline
\end{tabular}

- criterion considering information relevance

$$
\pi_{6}=\mathrm{Re}_{i}
$$

Considering the statistical measure used for estimation of the word importance in the document context which is being a part of documents collection (TF-IDF), it is possible to write down:

$$
\mathrm{Re}_{i}+\operatorname{Re}_{K}=1
$$

So, the criterion considering information relevance will be

$$
\pi_{6}=\mathrm{Re}_{i}=1-\mathrm{Re}_{K}
$$

where $\mathrm{Re}_{\mathrm{K}}$ - content relevance.

Subject to the data of Table 5 we will get the values of criterion $\pi_{6}$ (Table 6).

Table 6. Criterion Considering Information Relevance $\pi_{6}$

\begin{tabular}{|l|c|c|c|c|c|c|}
\hline$\pi_{5}$ & 0,19 & 0,43 & 0,61 & 0,73 & 0,85 & 0,97 \\
\hline
\end{tabular}

- criterion considering budget on functional perfection, budget on sales promotion and confidence module

$$
\pi_{7}=\frac{\psi \cdot B_{\phi}}{B_{n}+B_{\phi}}
$$

where $B_{\Phi}$ - budget on functional perfection, thousand rbl.; $B_{\Pi}$ - budget on sales promotion, thousand rbl.;

$\Psi$ - confidence module, $\%, \Psi=(R S H)$.

We will tabulate the input data and calculation results of criterion $\pi_{7}$.

Table 7. Input Data for Calculation of Criterion $\pi_{7}$

\begin{tabular}{|c|c|c|c|c|}
\hline $\begin{array}{c}\text { Budget for Functional } \\
\text { Perfection, thousand } \\
\text { rbl. } B_{\Phi}\end{array}$ & $\begin{array}{c}\text { Budget for Sales } \\
\text { Promotion, thousand } \\
\text { rbl.; } B_{\Pi}\end{array}$ & Confidence module, $\Psi$ & $\Psi B_{\Phi}$ & Criterion \\
\hline 11150 & 16650 & 0,75 & 8362,5 & 0,301 \\
\hline 27650 & 33150 & 0,75 & 20737,5 & 0,341 \\
\hline 44150 & 49650 & 0,75 & 33112,5 & 0,353 \\
\hline 60650 & 66150 & 0,75 & 45487,5 & 0,359 \\
\hline 77150 & 82650 & 0,75 & 57862,5 & 0,362 \\
\hline 99650 & 99150 & 0,75 & 7550237,5 & 0,364 \\
\hline
\end{tabular}


Table 8. Values of Similarity Criteria

\begin{tabular}{|c|c|c|c|c|c|c|}
\hline Criteria & 1 & 2 & 3 & 4 & 5 & 6 \\
\hline$\pi_{1}$ & 0,44 & 0,24 & 0,16 & 0,1 & 0,1 & 0,09 \\
\hline$\pi_{2}$ & 0,67 & 0,83 & 0,89 & 0,92 & 0,93 & 0,94 \\
\hline$\pi_{3}$ & 0,75 & 0,75 & 0,75 & 0,75 & 0,75 & 0,75 \\
\hline$\pi_{4}$ & 0,25 & 0,25 & 0,25 & 0,25 & 0,25 & 0,25 \\
\hline$\pi_{5}$ & 0,19 & 0,45 & 0,61 & 0,73 & 0,85 & 0,97 \\
\hline$\pi_{6}$ & 0,81 & 0,57 & 0,39 & 0,27 & 0,15 & 0,03 \\
\hline$\pi_{7}$ & 0,301 & 0,341 & 0,353 & 0,359 & 0,362 & 0,376 \\
\hline
\end{tabular}

Table 9. Criteria's Logarithms

\begin{tabular}{|c|c|c|c|c|c|c|}
\hline Criteria & 1 & 2 & 3 & 4 & 5 & 6 \\
\hline $\lg \pi_{1}$ & $-0,357$ & $-0,620$ & $-0,796$ & $-1,000$ & $-1,000$ & $-1,046$ \\
\hline $\lg \pi_{2}$ & $-0,174$ & $-0,081$ & $-0,051$ & $-0,036$ & $-0,032$ & $-0,027$ \\
\hline $\lg \pi_{3}$ & $-0,125$ & $-0,125$ & $-0,125$ & $-0,125$ & $-0,125$ & $-0,125$ \\
\hline $\lg \pi_{4}$ & $-0,602$ & $-0,602$ & $-0,602$ & $-0,602$ & $-0,602$ & $-0,602$ \\
\hline $\lg \pi_{5}$ & $-0,721$ & $-0,347$ & $-0,215$ & $-0,137$ & $-0,071$ & $-0,013$ \\
\hline $\lg \pi_{6}$ & $-0,092$ & $-0,260$ & $-0,409$ & $-0,569$ & $-0,824$ & $-1,523$ \\
\hline $\lg \pi_{7}$ & $-0,522$ & $-0,467$ & $-0,452$ & $-0,445$ & $-0,441$ & $-0,425$ \\
\hline
\end{tabular}

We will tabulate and find the logarithm of the received values of all the similarity criteria (Table 9).

Subject to the received similarity criteria mathematical model of demand volume can be presented in the form of criterion equation:

$\frac{N_{S}}{N_{P}}=\left(\frac{B_{\phi}}{B_{\Pi}}\right)^{\alpha_{2}} \cdot \psi^{\alpha_{3}} \cdot G^{\alpha_{4}} \cdot \operatorname{Re}_{K}^{\alpha_{5}} \cdot \operatorname{Re}_{i}^{\alpha_{6}} \cdot\left(\frac{\psi \cdot B_{\Phi}}{B_{\Pi}+B_{\Phi}}\right)^{\alpha_{7}}$

To define the unknown values of exponents $\alpha_{1}-\alpha_{7}$ we will make the system of equations

$$
\left\{\begin{array}{l}
\lg \pi_{11}=\alpha_{2} \lg \pi_{21}+\alpha_{3} \lg \pi_{31}+\alpha_{4} \lg \pi_{41} \\
+\alpha_{5} \lg \pi_{51}+\alpha_{6} \lg \pi_{61}+\alpha_{7} \lg \pi_{71} \\
\lg \pi_{12}=\alpha_{2} \lg \pi_{22}+\alpha_{3} \lg \pi_{32}+\alpha_{4} \lg \pi_{42} \\
+\alpha_{5} \lg \pi_{52}+\alpha_{6} \lg \pi_{62}+\alpha_{7} \lg \pi_{72} \\
\lg \pi_{13}=\alpha_{2} \lg \pi_{23}+\alpha_{3} \lg \pi_{33}+\alpha_{4} \lg \pi_{43} \\
+\alpha_{5} \lg \pi_{53}+\alpha_{6} \lg \pi_{63}+\alpha_{7} \lg \pi_{73} \\
\lg \pi_{14}=\alpha_{2} \lg \pi_{24}+\alpha_{3} \lg \pi_{34}+\alpha_{4} \lg \pi_{44} \\
+\alpha_{5} \lg \pi_{54}+\alpha_{6} \lg \pi_{64}+\alpha_{7} \lg \pi_{74} \\
\lg \pi_{15}=\alpha_{2} \lg \pi_{25}+\alpha_{3} \lg \pi_{35}+\alpha_{4} \lg \pi_{45} \\
+\alpha_{5} \lg \pi_{55}+\alpha_{6} \lg \pi_{65}+\alpha_{7} \lg \pi_{75} \\
\lg \pi_{16}=\alpha_{2} \lg \pi_{26}+\alpha_{3} \lg \pi_{36}+\alpha_{4} \lg \pi_{46} \\
+\alpha_{5} \lg \pi_{56}+\alpha_{6} \lg \pi_{66}+\alpha_{7} \lg \pi_{76}
\end{array}\right.
$$

Let's substitute the criteria value from Table 9 in the system presented above and we will get

$$
\left\{\begin{array}{l}
-0,357=-0,174 \alpha_{2}-0,125 \alpha_{3}-0,602 \alpha_{4} \\
-0,721 \alpha_{5}-0,092 \alpha_{6}-0,522 \alpha_{7} \\
-0,62=-0,081 \alpha_{2}-0,125 \alpha_{3}-0,602 \alpha_{4} \\
-0,347 \alpha_{5}-0,26 \alpha_{6}-0,467 \alpha_{7} \\
-0,796=-0,051 \alpha_{2}-0,125 \alpha_{3}-0,602 \alpha_{4} \\
-0,215 \alpha_{5}-0,409 \alpha_{6}-0,452 \alpha_{7} \\
-1=-0,036 \alpha_{2}-0,125 \alpha_{3}-0,602 \alpha_{4} \\
-0,137 \alpha_{5}-0,569 \alpha_{6}-0,445 \alpha_{7} \\
-1=-0,032 \alpha_{2}-0,125 \alpha_{3}-0,602 \alpha_{4} \\
-0,071 \alpha_{5}-0,824 \alpha_{6}-0,441 \alpha_{7} \\
-1,046=-0,027 \alpha_{2}-0,125 \alpha_{3}-0,602 \alpha_{4} \\
-0,013 \alpha_{5}-1,523 \alpha_{6}-0,425 \alpha_{7}
\end{array}\right.
$$

Table 10. System Matrix

\begin{tabular}{|c|c|c|c|c|c|c|}
\hline-357 & -174 & -125 & -602 & -721 & -92 & -522 \\
\hline-620 & -81 & -125 & -602 & -347 & -260 & -467 \\
\hline-796 & -51 & -125 & -602 & -215 & -409 & -452 \\
\hline-1000 & -36 & -125 & -602 & -137 & -569 & -445 \\
\hline-1000 & -32 & -125 & -602 & -71 & -824 & -441 \\
\hline-1046 & -27 & -125 & -602 & -13 & -1523 & -425 \\
\hline
\end{tabular}


Let's transform this system of equations multiplying both parts of each equation in the system by 1000 , and we will draw up system matrix (Table 10):

$$
\left\{\begin{array}{l}
-357=-174 \alpha_{2}-125 \alpha_{3}-602 \alpha_{4} \\
-721 \alpha_{5}-92 \alpha_{6}-522 \alpha_{7} \\
-620=-81 \alpha_{2}-125 \alpha_{3}-602 \alpha_{4} \\
-347 \alpha_{5}-26 \alpha_{6}-467 \alpha_{7} \\
-796=-51 \alpha_{2}-125 \alpha_{3}-602 \alpha_{4} \\
-215 \alpha_{5}-409 \alpha_{6}-452 \alpha_{7} \\
-1000=-36 \alpha_{2}-125 \alpha_{3}-602 \alpha_{4} \\
-137 \alpha_{5}-569 \alpha_{6}-445 \alpha_{7} \\
-1000=-32 \alpha_{2}-125 \alpha_{3}-602 \alpha_{4} \\
-71 \alpha_{5}-824 \alpha_{6}-441 \alpha_{7} \\
-1046=-27 \alpha_{2}-125 \alpha_{3}-602 \alpha_{4} \\
-13 \alpha_{5}-1523 \alpha_{6}-425 \alpha_{7}
\end{array}\right.
$$

Expanded Matrix Determinant:

$$
\Delta_{M}=\left|\begin{array}{llllllll}
-357 & -174 & -125 & -602 & -721 & -92 & -522 \\
-620 & -81 & -125 & -602 & -347 & -260 & -467 \\
-796 & -51 & -125 & -602 & -215 & -409 & -452 \\
-1000 & -36 & -125 & -602 & -137 & -569 & -445 \\
-1000 & -32 & -125 & -602 & -71 & -824 & -441 \\
-1046 & -27 & -125 & -602 & -13 & -1523 & -425
\end{array}\right|
$$

We will make a decision according to Cramer's rule. The main determinant or system determinant will be:

$$
\Delta_{\infty}=\left|\begin{array}{rrrrrr}
-174 & -125 & -602 & -721 & -92 & -522 \\
-81 & -125 & -602 & -347 & -260 & -467 \\
-51 & -125 & -602 & -215 & -409 & -452 \\
-36 & -125 & -602 & -137 & -569 & -445 \\
-32 & -125 & -602 & -71 & -824 & -441 \\
-27 & -125 & -602 & -13 & -1523 & -425
\end{array}\right|=-0,00013
$$

We find determinants for calculation of unknown $\alpha_{2}, \alpha_{3}, \alpha_{4}$, $\alpha_{5}, \alpha_{6}, \alpha_{7}$, substituting a column of absolute terms on their places:

$$
\left(\begin{array}{l}
-357 \\
-620 \\
-796 \\
-1000 \\
-1000 \\
-1046
\end{array}\right)
$$

The1st determinant for calculation $\alpha_{2}$ :

$$
\Delta_{1}=\left|\begin{array}{rrrrrr}
-357 & -125 & -602 & -721 & -92 & -522 \\
-620 & -125 & -602 & -347 & -260 & -467 \\
-796 & -125 & -602 & -215 & -409 & -452 \\
-1000 & -125 & -602 & -137 & -569 & -445 \\
-1000 & -125 & -602 & -71 & -824 & -441 \\
-1046 & -125 & -602 & -13 & -1523 & -425
\end{array}\right|=0,0067
$$

The 2nd determinant for calculation $\alpha_{3}$ :

$$
\Delta_{2}=\left|\begin{array}{rrrrrr}
-174 & -357 & -602 & -721 & -92 & -522 \\
-81 & -620 & -602 & -347 & -260 & -467 \\
-51 & -796 & -602 & -215 & -409 & -452 \\
-36 & -1000 & -602 & -137 & -569 & -445 \\
-32 & -1000 & -602 & -71 & -824 & -441 \\
-27 & -1046 & -602 & -13 & -1523 & -425
\end{array}\right|=-4,66 \cdot 10^{11}
$$

The 3rd determinant for calculation $\alpha_{4}$ :

$$
\Delta_{3}=\left|\begin{array}{rrrrrr}
-174 & -125 & -357 & -721 & -92 & -522 \\
-81 & -125 & -620 & -347 & -260 & -467 \\
-51 & -125 & -796 & -215 & -409 & -452 \\
-36 & -125 & -1000 & -137 & -569 & -445 \\
-32 & -125 & -1000 & -71 & -824 & -441 \\
-27 & -125 & -1046 & -13 & -1523 & -425
\end{array}\right|=9,68 \cdot 10^{10}
$$

The 4th determinant for calculation $\alpha_{5}$ : 
$\Delta_{4}=\left|\begin{array}{rrrrrr}-174 & -125 & -602 & -357 & -92 & -522 \\ -81 & -125 & -602 & -620 & -260 & -467 \\ -51 & -125 & -602 & -796 & -409 & -452 \\ -36 & -125 & -602 & -1000 & -569 & -445 \\ -32 & -125 & -602 & -1000 & -824 & -441 \\ -27 & -125 & -602 & -1046 & -1523 & -425\end{array}\right|=-0,00048$

The 5 th determinant for calculation $\alpha 6$.

$$
\Delta_{5}=\left|\begin{array}{rrrrrr}
-174 & -125 & -602 & -721 & -357 & -522 \\
-81 & -125 & -602 & -347 & -620 & -467 \\
-51 & -125 & -602 & -215 & -796 & -452 \\
-36 & -125 & -602 & -137 & -1000 & -445 \\
-32 & -125 & -602 & -71 & -1000 & -441 \\
-27 & -125 & -602 & -13 & -1046 & -425
\end{array}\right|=-0,00012
$$

The 6 th determinant for calculation $\alpha_{7}$ :

$$
\Delta_{6}=\left|\begin{array}{lllllll}
-174 & -125 & -602 & -721 & -92 & -357 \\
-81 & -125 & -602 & -347 & -260 & -620 \\
-51 & -125 & -602 & -215 & -409 & -796 \\
-36 & -125 & -602 & -137 & -569 & -1000 \\
-32 & -125 & -602 & -71 & -824 & -1000 \\
-27 & -125 & -602 & -13 & -1523 & -1046
\end{array}\right|=-0,004
$$

Let's define the exponents for criterion equation (2):

$$
\begin{gathered}
\alpha_{2}=\Delta_{1} / \Delta \approx-53,15 \\
\alpha_{3}=\Delta_{2} / \Delta \approx 3,6910^{15} \\
\alpha_{4}=\Delta_{3} / \Delta \approx-7,6710^{14} \\
\alpha_{5}=\Delta_{4} / \Delta \approx 3,79 \\
\alpha_{6}=\Delta_{5} / \Delta \approx 0,93 \\
\alpha_{7}=\Delta_{6} / \Delta \approx 32,58
\end{gathered}
$$

Let's substitute the exponents in the equation (2):

$$
\begin{aligned}
& \frac{N_{S}}{\mathrm{~N}_{p}}=\left(\frac{B_{\Phi}}{B_{\Pi}}\right)^{-53,15} \cdot \psi^{3,69 \cdot 10^{15}} \cdot G^{-7,67 \cdot 10^{14}} \\
& \cdot \operatorname{Re}_{K}^{3,79} \cdot \operatorname{Re}_{i}^{0,93} \cdot\left(\frac{\psi \cdot B_{\Phi}}{B_{\Pi}+B_{\Phi}}\right)^{32,58}
\end{aligned}
$$

Let's express $N_{S}$ from expression (3) and we will get mathematical model of production demand volume in the final form:

$$
\begin{aligned}
& N_{S}=N_{p}\left(\frac{B_{\Phi}}{B_{\Pi}}\right)^{-53,15} \cdot \psi^{3,69 \cdot 10^{15}} \cdot G^{-7,67 \cdot 10^{14}} \\
& \cdot \operatorname{Re}_{K}^{3,79} \cdot \operatorname{Re}_{i}^{0,93} \cdot\left(\frac{\psi \cdot B_{\Phi}}{B_{\Pi}+B_{\Phi}}\right)^{32,58}
\end{aligned}
$$

Disclosing the criteria values $\psi=R S H$ and $\mathrm{Re}_{\mathrm{i}}=$ $1-\mathrm{Re}_{\mathrm{K}}$, we will get the expanded model for defining production demand volume of the considered enterprises.

$$
\begin{aligned}
& N_{S}=N_{p}\left(\frac{B_{\Phi}}{B_{\Pi}}\right)^{-53,15} \cdot(R S H)^{3,69 \cdot 10^{15}} \cdot G^{-7,67 \cdot 10^{14}} \\
& \cdot \operatorname{Re}_{K}^{3,79} \cdot\left(1-\mathrm{Re}_{K}\right)^{0,93} \cdot\left(\frac{\psi \cdot B_{\Phi}}{B_{\Pi}+B_{\Phi}}\right)^{32,58}
\end{aligned}
$$

The required mathematical model of production demand volume (of the enterprises of Russia timber industry chosen by us) reflects the positive tendency of Internet marketing, especially regarding advertising budget of the enterprise which lays the foundation for the further research of the market. Factors $\alpha_{2}, \alpha_{3}, \alpha_{4}, \alpha_{5}, \alpha_{6}, \alpha_{7}$, being a part of the model, dictate market conditions and its development dynamics.

This model can be used for estimation of production demand volume of any orientation, and the presented method of factors account will be useful for modeling of the demand function at any level of economic system, for private markets and for macroeconomics.

\section{Advertising Quality Estimation on the Company's Site with Modified Danaher - Rust Model}

Relying on Danaher-Rust model to define enterprise's advertising budget, it is possible to make a forecast of enterprise's advertising site, estimating advertising quality on the following criteria $[5,6,8,19]$ : accessibility, relevance and confidence.

The basic calculation operations should be done on the statistical data.

Let's consider Danaher-Rust model $[5,6,8,19]$ :

$$
\mathrm{E}=\mathrm{k} \cdot \mathrm{f}-\mathrm{c} \text {, }
$$

where $E$ - enterprise's profitability due to advertising on the Internet site;

$k$ - money terms of one unit of advertising efficiency.

$f$ - indicator of advertising efficiency. (We will carry out estimation according to the number of clients who has made purchase due to advertising on the enterprise's Internet site.) $c$ - advertising rate.

Money terms of one unit of advertising efficiency will be 
estimated according to the average value

$$
k=\frac{\sum_{i=1}^{n} x_{i}}{n}
$$

where $x_{i}$ - amount spent for production purchase;

$n$-number of the clients who have made purchases.

We will accept the number of the clients who have made purchases $n$ as an indicator of advertising efficiency $f$, and will write down

$$
\mathrm{f}=\mathrm{n}=\beta \cdot \mathrm{N}_{\mathrm{p}}
$$

where $\beta$ - percent of the number of clients $N_{p}$ who visited the site and made purchase;

$$
\beta=\alpha+\gamma+\eta
$$

where $\alpha$ - percent of the clients considering the competitors' offers, but using Internet site service;

$\gamma$-percent of clients who visited the site and did not consider other offers;

$\eta$ - the percent of the clients who made purchase, but who are not satisfied with the given content relevance, and do not want to use the service of the company any more. t].

The functions are considered in a certain time interval $[0$;

Efficiency of advertising influence will be presented by the sum $\alpha(t)+\gamma(t)$.

Considering these functions, we will rewrite the model (6) in the form:

$$
\mathrm{E}=\mathrm{k} \cdot \beta \cdot \mathrm{N}_{\mathrm{p}}-\mathrm{c}
$$

or

$$
\mathrm{E}(\mathrm{t})=\mathrm{k}(\mathrm{t}) \cdot \beta(\mathrm{t}) \cdot \mathrm{N}_{\mathrm{p}}(\mathrm{t})-\mathrm{c}(\mathrm{t})
$$

As $\beta(t)=\alpha(t)+\gamma(t)+\eta(t)$ we will finally write down:

$\mathrm{E}(\mathrm{t})=\mathrm{k}(\mathrm{t}) \cdot(\alpha(\mathrm{t})+\gamma(\mathrm{t})+\eta(\mathrm{t})) \cdot \mathrm{N}_{\mathrm{p}}(\mathrm{t})-\mathrm{c}(\mathrm{t})$.

As these functions vary eventually, it is necessary to make constant some functions of time in the time interval chosen by us to define advertising efficiency on the Internet site.

Let $\mathrm{k}(\mathrm{t}) \cdot=$ const, $\mathrm{N}_{\mathrm{p}}(\mathrm{t})=$ const, then

$\mathrm{E}(\mathrm{t})=\mathrm{k} \cdot \mathrm{N}_{\mathrm{p}}(\alpha(\mathrm{t})+\gamma(\mathrm{t})+\eta(\mathrm{t}))-\mathrm{c}(\mathrm{t})$.

The maximum profit from advertising $E(t)$ will depend on influence efficiency $\alpha(t)+\gamma(t)$.

We will define function maximum from the condition:

$$
\begin{gathered}
\frac{d E}{d t}=0 \\
\frac{d E}{d t}=k \cdot N_{p}\left(\frac{d \alpha}{d t}+\frac{d \gamma}{d t}+\frac{d \eta}{d t}\right)-\frac{d c}{d t}
\end{gathered}
$$

Let's introduce the substitute:

$$
\alpha_{1}=\frac{d \alpha}{d t} \quad \gamma_{1}=\frac{d \gamma}{d t}, \quad \eta_{1}=\frac{d \eta}{d t}, \quad c_{1}=\frac{d c}{d t}
$$

Then, taking into consideration the condition, that $\frac{d E}{d t}=0$, $k \cdot N_{p}\left(\alpha_{1}+\gamma_{1}+\eta_{l}\right)-c_{1}=0$

we carry out transformation:

$$
\alpha_{1}+\gamma_{1}+\eta_{1}=\frac{c_{1}}{k \cdot N_{p}}
$$

Let's represent efficiency of advertising influence

$$
\alpha_{1}+\gamma_{1}=\frac{c_{1}}{k \cdot N_{p}}-\eta_{1}
$$

Advertising price $c_{1}$ will depend on the functional development budget

$$
\mathrm{c}_{1}=\mathrm{B}_{\mathrm{o \phi}}-\mathrm{B \phi}
$$

where $B_{o \phi}$ - budget at the moment of time $\mathrm{t}=0$;

$v f$ - budget at the moment of time t.

Rate of budget change

$$
\frac{d B_{\phi}}{d t}=-r \cdot B_{\phi}
$$

where $r$ - budget change factor.

Let's set up differential equation, using expression (8):

$$
\frac{d B_{\phi}}{B_{\phi}}=-r \cdot d t
$$

Let's integrate the expression

$$
\begin{gathered}
\int \frac{d B_{\phi}}{B_{\phi}}=-\int r \cdot d t \\
\ln B_{\phi}=-r \cdot t+\ln c_{0}
\end{gathered}
$$

where $c_{0}$ - constant of the general solution of the differential equation

$$
\begin{gathered}
\mathrm{c}_{0}=\text { const, } \mathrm{c}_{0} \neq 0 \\
B_{\phi}=e^{-r \cdot t+\ln c_{0}} \\
B_{\phi}=e^{-r \cdot t}+e^{\ln c_{0}} \\
B_{\phi}=c_{0} e^{-r \cdot t} \\
\text { At } t=0, c_{0}=B_{o \phi}
\end{gathered}
$$

Then, the budget change is

$$
B_{\phi}=B_{o \phi} \cdot e^{-r \cdot t}
$$

Price of advertising placed on the Internet site is:

$$
c=B_{o \phi}-B_{\phi}
$$




$$
c=B_{o \phi}-B_{o \phi} \cdot e^{-r \cdot t} .
$$

In the final form:

$$
c=B_{o \phi}\left(1-\cdot e^{-r \cdot t}\right)
$$

Then, $c_{1}=\frac{d c}{d t}=B_{o \phi} \cdot r \cdot e^{-r \cdot t}$

Let's put the received expression in the assumption formula of advertising influence efficiency and we will get the formula for defining advertising efficiency

$$
\left(\alpha_{1}+\gamma_{1}\right)=\frac{B_{o \phi} \cdot r \cdot e^{-r \cdot t}}{k \cdot N_{p}}-\eta_{1}
$$

Expression (9) can be presented graphically on the considered interval of time $[0 ; 150]$ (days) at invariable price of advertising $\mathrm{c}=$ const (Figure 1).

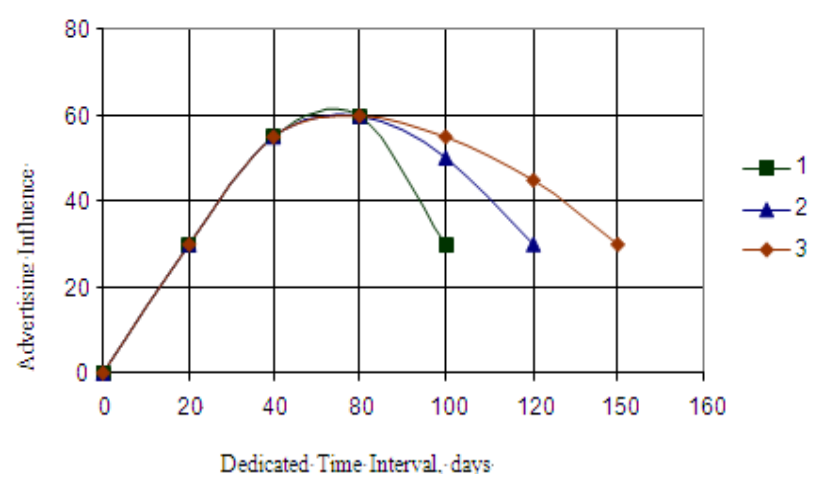

Curve 1. Advertising Efficiency at $\eta 1$;

Curve 2. - Advertising Efficiency at $\eta 2$;

Curve 3. - Advertising Efficiency at $\eta 3$;

Values $\eta 1>\eta 2>\eta 3$

Figure 1. Advertising Efficiency When Advertising Price Is Invariable

Taking into consideration statistical data and advertising efficiency estimation according to the so-called "CTR response" (Click-Through Rate), advertising efficiency $\left(\alpha_{1}+\gamma_{1}\right)$ expressed in percent (\%) fluctuates in the interval $[0 ; 60]$ at the general dedicated time interval (days) $[0 ; 150]$. I.e.

$$
\left(\alpha_{1}+\gamma_{1}\right)_{\max }=60 \% .
$$

According to the researches of the prominent American marketer Stephen Shiffman [25] peak advertising efficiency $\left(\alpha_{1}+\gamma_{1}\right)_{\max }=60 \%$ at the stable market is possible in the time interval $[0 ; 90]$ days, at a constant price $(\mathrm{c}=$ const $)$ and insignificant fluctuation of currencies rate influencing money terms of advertising efficiency unit $k$.

Peak advertising efficiency can promote $\eta$ percent growth of the clients who have made purchase, but who are not satisfied with the content relevance, and who are not going to use the service of the company any more. It is caused, first of all, by demand increase (thousand people) and competitors' activity on damping the services prices.

Values $t_{1}, t_{2}, t_{3}$ correspond to the period of time when advertising efficiency can decrease 2 times. The rate of this curve will depend, first of all, on company's "readiness" for the recession.

Figure 2 presents the dependence diagram of advertising on the time interval at constant value of clients percent who made purchase, but was not satisfied with of the content relevance, and is not going to use the service of the company any more.

The time interval of achieving advertising peak efficiency will depend on the enterprise's liquidity, i.e. directly depends on advertising price $c$ and money terms of one advertising efficiency unit $k$. Time of achieving peak efficiency $\left(\alpha_{1}+\gamma_{1}\right)_{\max }=60 \%$ will depend on how much the enterprises will invest in advertising. At the interval preset value $[0 ; 150]$ time of achieving peak efficiency is $t_{\max 1}=40$ days; $\mathrm{t}_{\max 2}=60$ days; $\mathrm{t}_{\max 3}=80$ days. Dip of curve is caused, first of all, by the currency rate fluctuation and, hence, by advertising price.

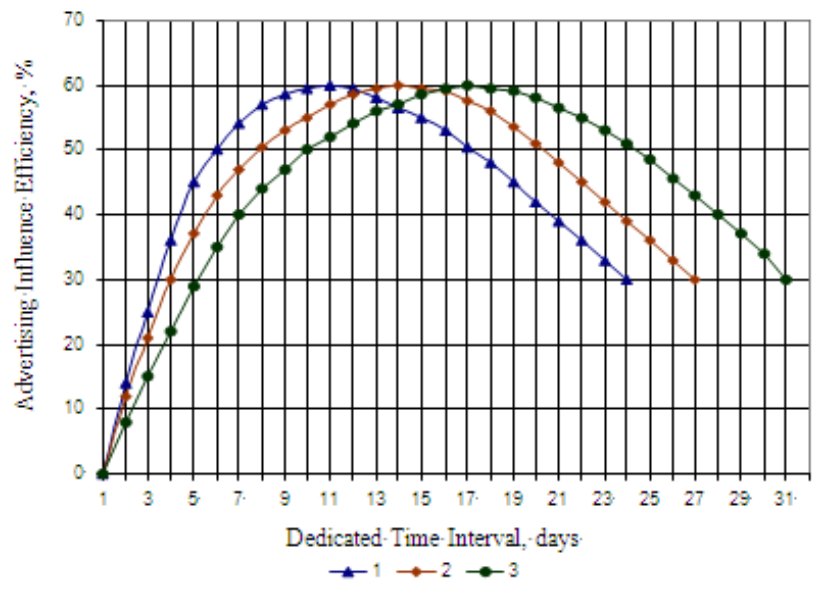

Curve 1. Advertising efficiency at advertising price $\mathrm{c}_{1}$ and money terms of one unit of advertising efficiency $\mathrm{k}_{1}$;

Curve 2. Advertising efficiency at advertising price $c_{2}$ and money terms of one unit of advertising efficiency $\mathrm{k}_{2}$;

Curve 3. Advertising efficiency at advertising price $c_{3}$ and money terms of one unit of advertising efficiency $\mathrm{k}_{3}$;

Values $\mathrm{c}_{1}<\mathrm{c}_{2}<\mathrm{c}_{3} \mathrm{k}_{1}>\mathrm{k}_{2}>\mathrm{k}_{3}$

Figure 2. Advertising Efficiency at $\eta=$ const of Clients Percent who Made a Purchase, But who are not Satisfied with Content Relevance, and who don't Want to Use the Service of the Company any more

Summarizing the stated above, it is possible to draw a conclusion, that the formula of Danaher-Rust model implicitly reflects the values influencing dynamics of production demand growth of the enterprise.

Profitability of the enterprise from Internet advertising activity presented in the model is a multivalued function depending not only on three variables $E_{A}=F(k, f, c)$.

Parametres $k$ and $f$ are subjective enough and require detailed disclosing. And enterprise's profitability estimation, thanks to Internet advertising, is also approximate enough.

Therefore, it is necessary to estimate the site hits, thereby, passing to advertising efficiency which, in turn, changes very 
dynamically depending on the market situation.

\section{REFERENCES}

[1] Baohong Sun, Promotion Effect on Endogenous Consumption, Marketing Science, Vol. 24, No. 3 (Summer, 2005), pp. 430-443

[2] Christian M. Derbaix, The Impact of Affective Reactions on Attitudes toward the Advertisement and the Brand: A Step toward Ecological Validity, Journal of Marketing Research, Vol. 32, No. 4 (Nov., 1995), pp. 470-479

[3] Danaher, P.J. and Rust, R.T. (1992), Linking Segmentation Studies, Journal of Advertising Research, June, 32, 3, 18-23.

[4] Danaher, P.J. and Rust, R.T. (1993), Exposure Distributions in Target Markets, Journal of Current Issues and Research in Advertising, 15, Spring, 77-86.

[5] Danaher, P.J. and Rust, R.T. (1994), Determining the Optimal Level of Media Spending, Journal of Advertising Research, January, 34, 1, 28-34.

[6] Danaher, P.J. and Rust, R.T. (1996), Determining the Optimal Return on Investment for an Advertising Campaign, European Journal of Operations Research, 95, 511-521.

[7] Danaher, P.J. and Rust, R.T. (1996), Indirect Marketing Benefits From Service Quality, (with discussion and rejoinder), Quality Management Journal, 3, 2, 63-88.

[8] Daniel S. Diamond, A Quantitative Approach to Magazine Advertisement Format Selection, Journal of Marketing Research, Vol. 5, No. 4 (Nov., 1968), pp. 376-386

[9] David A. Schweidel, Eric T. Bradlow, Patti Williams, A Feature-Based Approach to Assessing Advertisement Similarity, Journal of Marketing Research, Vol. 43, No. 2 (May, 2006), pp. 237-243

[10] Eric Breitbart, The Burns Effect: Documentary as Celebrity Advertisement, New England Review (1990), Vol. 28, No. 1 (2007), pp. 168-178

[11] George C. Davis, The Significance and Insignificance of Demand Analysis in Evaluating Promotion Programs, American Journal of Agricultural Economics, Vol. 87, No. 3 (Aug., 2005), pp. 673-688

[12] H.-Y. Tsao, P.-C. Lin, L. Pitt, C. Campbell, The Impact of Loyalty and Promotion Effects on Retention Rate, The Journal of the Operational Research Society, Vol. 60, No. 5 (May, 2009), pp. 646-651

[13] Jaideep Sengupta, Gerald J. Gorn, Absence Makes the Mind
Grow Sharper: Effects of Element Omission on Subsequent Recall, Journal of Marketing Research, Vol. 39, No. 2 (May, 2002), pp. 186-201

[14] Judith A. Garretson, Scot Burton, The Role of Spokescharacters as Advertisement and Package Cues in Integrated Marketing Communications, Journal of Marketing, Vol. 69, No. 4 (Oct., 2005), pp. 118-132

[15] Karen A. Machleit, R. Dale Wilson, Emotional Feelings and Attitude toward the Advertisement: The Roles of Brand Familarity and Repetition, Journal of Advertising, Vol. 17, No. 3 (1988), pp. 27-35

[16] Peter J. Danaher, A Markov-Chain Model for Multivariate Magazine-Exposure Distributions, Journal of Business AND Economic Statistics, Vol. 10, No. 4 (Oct., 1992), pp. 401-407

[17] Prashant Malaviya, Jolita Kisielius, Brian Sternthal, The Effect of Type of Elaboration on Advertisement Processing and Judgment, Journal of Marketing Research, Vol. 33, No. 4 (Nov., 1996), pp. 410-421

[18] 18. Ronald L. Earl, William M. Pride, The Effects of Advertisement Structure, Message Sidedness, and Performance Test Results on Print Advertisement Informativeness, Journal of Advertising, Vol. 9, No. 3 (1980), pp. 36-44

[19] Rust, R.T., Danaher, P.J. and Varki, S. (2000), Using Service Quality Data for Competitive Marketing Decisions, International Journal of Service Industry Management, 11, 5, 438-469.

[20] Stephen Brown, Lorna Stevens, Pauline Maclaran, I Can't Believe It's Not Bakhtin!: Literary Theory, Postmodern Advertising, and the Gender Agenda, Journal of Advertising, Vol. 28, No. 1, Gender and Multicultural Issues (Spring, 1999), pp. 11-24

[21] T V. Sethuraman, K. T. George, On Optimisation of Advertisement Cost, Indian Journal of Industrial Relations, Vol. 19, No. 2 (Oct., 1983), pp. 235-239.

[22] Thierry Lodé, Dominique Le Jacques, Influence of Advertisement Calls on Reproductive Success in the Male Midwife Toad Alytes obstetricans, Behaviour, Vol. 140, No. 7 (Jul., 2003), pp. 885-898

[23] Similarity Theory and Modelling as Applied to Electricity. Available at: http://ru.wikipedia.org >wiki/Similarity_Criteri on (accessed 22 February 2013)

[24] Similarity Theory and Modelling as Applied to Electricity. Available at: http://slovari.yandex.ru > knigi/ Great Soviet Encyclopedia /Similarity Theory / (accessed 22 February 2013)

[25] Steve Schiffman. Available at: http://www.steveschiffman.c om (accessed 7 February 2013). 